\title{
Mecanismo de Contenção na Doença Venosa
}

\author{
Godoy JMP. ${ }^{1}$ \\ ${ }^{1}$ São Paulo - Brasil. \\ E-mail: godoyjmp@gmail.com
}

Godoy, J.M.P. 2013. Mecanismo de Contenção na Doença Venosa, p.65. In: Bastos, Francisco Reis. Anais do V Simpósio Internacional de Flebologia [Blucher Medical Proceedings n.1 v.1]. São Paulo: Blucher, 2014 http://dx.doi.org/10.5151/medpro-flebo-SIF_39

\section{Introdução}

As meias elásticas e as bandagens constituem importantes mecanismos potencializadores do retorno venoso e linfático, sendo indicados no tratamento de doenças venosas. O retorno venolinfático ocorre de forma fisiológica,contudo a interferência da pressão gravitacional exige mecanismos compensadores para manter o equilíbrio da drenagem desses fluidos. O edema é a resultante dos efeitos da pressão gravitacional, levando a sinais e sintomas clínicos.

\section{Método}

Revisão de literatura e experiência pessoal.

\section{Resultado}

Os mecanismos de contenção interferem no mecanismo de hidrodinâmica desses fluidos exercendo duas pressões que são fundamentais na potencialização do deslocamento dos fluidos intravasos e no espaço intersticial. A pressão de repouso é mensurada na interface meia/ pele sem interferência da atividade muscular. Pressão de trabalho sofre interferência da atividade muscular realizada que desenvolve uma pressão de pulso na interface pele/meia. Dessa forma tanto os mecanismos elásticos como os não elásticos podem auxiliar no retorno venolinfático. As meias elásticas constituem na principal opção clínica no tratamento da doença venosa, porém exige uma correta adaptação para cada paciente. As dobras e a perda da elasticidade podem levar à falha terapêutica.

\section{Conclusão}

As meias elásticas e as bandagens constituem em importantes mecanismos potencializadores no retorno veno-linfático.

Palavras-Chave: Mecanismo de contenção, doenças venosa. 